日臨外会誌 $66(3), 697-701,2005$

症例

膵頭部腫瘤の鑑別診断に FDG-PET が有用であった 1 例

石川県立中央病院一般消化器外科

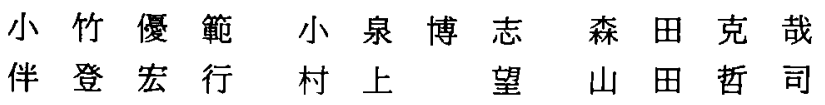

症例は62歳, 男性. 2003年12月下旬に腹痛を自覚し近医を受診し，精査にて膆頭部癌 が疑われ，2004年 1 月 9 日手術目的に当科紹介となった。腫璄マーカーは陰性で，腹部 $\mathrm{CT} \cdot \mathrm{MRI} て ゙ は$ 膵頭部に約 $4 \mathrm{~cm}$ 大の腫瘤と周囲リンパ節の腫大を認めた. ERCP では， 膵頭部の主膵管に狭窄はあるが壁はスムースで, 腹部血管造影検查では異常所見は認め ず. FDG-PET では膵全体に糖代謝穴進を認めるも，覀性所見を思わせる限局した集積 は認めず. 以上より腫瘤形成性膵炎もしくは抗核抗体, IgG4の高值より自己免疫性膵炎 などの良性疾患を疑い経過観察とした. 3 力月後の腹部 CT では脺頭部の腫大は改善し, 周囲のリンパ節腫大も認めず. FDG-PETでも脺への集稓は認めず。以上より一過性に 膵頭部腫大をきたしたアルコール性膵炎であったと考えられた.FDG-PET は脺疾患に おいて鑑別に非常に有用である検査方法であると考えられた。

卖引用語：膵頭部腫痹, FDG-PET, 急性膵炎

\section{緒 言}

腫㿔形成性膵炎と膵癌の良悪性の鑑別には多種多彩 な検查方法があるが, 最新の画像診断法を駆使しても 診断に難橴することが多い.今回, FDG-PET 検査が 膵頭部腫瘤の良悪性の鑑別に有用であったので報告す る.

\section{症 例}

患者：62歳, 男性.

主訴：腹痛。

既往歴：30年前に胃潰瘍.

家族歴：特記すべき事項なし.

㖺好歴：アルコール (日本酒：7〜8合).

現病歴：2003年12月27日より腹痛を認め, 改善しな いため12月29日近医を受診し入院となった. CT, MRI 検查にて膵頭部に $4 \mathrm{~cm}$ 大の腫瘤を認め, 膵癌の可能 性もあり2004年 1 月 9 日手術目的に転院となった。

入院時現症：身長 $160 \mathrm{~cm}$, 体重 $59 \mathrm{Kg}$, 血圧 $110 / 60$ $\mathrm{mmHg}$, 脈拍 $72 /$ 分, 体温 $36.7^{\circ} \mathrm{C}$, 眼球結膜に黄染なく, 眼瞼結膜に貧血は認めなかった，上腹部に軽度の圧痛

2004年11月 2 日受付 2005 年 1 月 5 日採用 〈所属施設住所〉

$\overline{\mathbf{T}} 920-8530$ 金沢市转月東 $2-1$
は認めるが，筋性防御はなく，腫瘤を触知しなかった。 表在リンパ節も触知しなかった。

入院時検查所見 : Amy, CRP は前医での治療にて 改善しており, ALP・ $\gamma$-GTP・リパーゼ・ZTT・TTT の上昇を認めた。腫腸マーカー (CEA ・CA19-9・ DUPAN-2・Span-1) はすべて正常範囲内であった（表 1 ).

腹部 CT 検査 (図 1)：膵頭部に $4 \times 2 \mathrm{~cm}$ 大の腫瘤 を認め, 内部は壊死を疑わせる低吸収域を示し, 造影 で軽度に増強された，周囲リンパ節の腫大を認めた。 主膵管は軽度の拡張を認めるも，総胆管には拡張を認 めず, 腹水も認めなかった。

腹部 MRI 検査：膵頭部に $4 \mathrm{~cm}$ 大の腫瘤を認め, T1およびT2にて低信号を呈し, 造影にて早期相(図 2 a) では造影効果は乏しく後期相（図 2 b) て增強し ており，㵶維成分の多い腫瘤であると考えられた。

逆行性胆膆管造影検査 (図 3 ) : 膵頭部の主膵管は圧 排・狭窄を認めたが, 壁はスムースで末梢主膵管の拡 張も認めなかった。

腹部血管造影検查 : 腹腔動脈および上腸間膜動脈の 本幹および主要分枝には，腫瘍浸潤を疑う所見なく， 脺頭部のアーケードにも断裂や広狭不整所見は認めな かった。門脈・脾静脈・上腸間膜静脈にも狭窄・閉塞 
表 1 入院時検査成績

\begin{tabular}{|c|c|c|c|c|}
\hline WBC & 54 & $\times 10^{2} / \mathrm{m}^{3}$ & $\mathrm{~T}-\mathrm{Bil}$ & $0.93 \mathrm{mg} / \mathrm{dl}$ \\
\hline $\mathrm{RBC}$ & 412 & $\times 10^{4} / \mathrm{m}^{3}$ & Alp & $\underline{513} \mathrm{IU} / \mathrm{l}$ \\
\hline $\mathrm{Hb}$ & 12.8 & $\mathrm{~g} / \mathrm{dl}$ & ZTT & $\underline{15.2} \mathrm{KU}$ \\
\hline $\mathrm{Ht}$ & 37.3 & ${ }^{\circ}{ }_{0}$ & TTT & $\underline{8.6} \mathrm{KU}$ \\
\hline \multirow[t]{2}{*}{ Plts } & 24.8 & $/ \mathrm{m}^{3}$ & GOT & $\mathrm{IU} / \mathrm{l}$ \\
\hline & & & GPT & IU/1 \\
\hline CEA & $<1.0$ & $\mathrm{ng} / \mathrm{ml}$ & $\mathrm{LDH}$ & $164 \mathrm{IU} / \mathrm{I}$ \\
\hline CA19-9 & 14.7 & $\mathrm{U} / \mathrm{ml}$ & $\gamma-\mathrm{GTP}$ & $\underline{223} \mathrm{IU} / 1$ \\
\hline DUPAN-2 & $<25$ & $\mathrm{U} / \mathrm{ml}$ & BUN & $11.7 \mathrm{mg} / \mathrm{dl}$ \\
\hline \multirow[t]{2}{*}{ Span-1 } & 15 & $\mathrm{U} / \mathrm{ml}$ & $\mathrm{Cr}$ & $0.91 \mathrm{mg} / \mathrm{dl}$ \\
\hline & & & リパーゼ & $\underline{71} \mathrm{U} / 1$ \\
\hline ANA & $\times 811$ & & Amy & $\overline{113} \mathrm{IU} / \mathrm{l}$ \\
\hline $\operatorname{IgG} 4$ & $\underline{92}$ & & & (前医645） \\
\hline \multirow[t]{2}{*}{ CRP } & $\overline{1.6}$ & $\mathrm{mg} / \mathrm{dl}$ & $\mathrm{HBsAg}$ & $(-)$ \\
\hline & （前医 & & $\mathrm{HCVAb}$ & $(-)$ \\
\hline
\end{tabular}

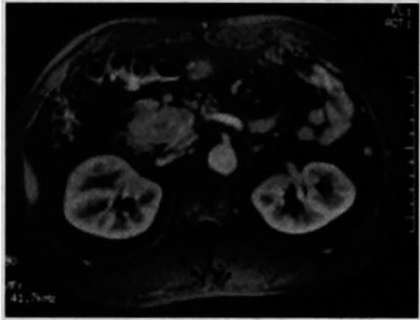

a

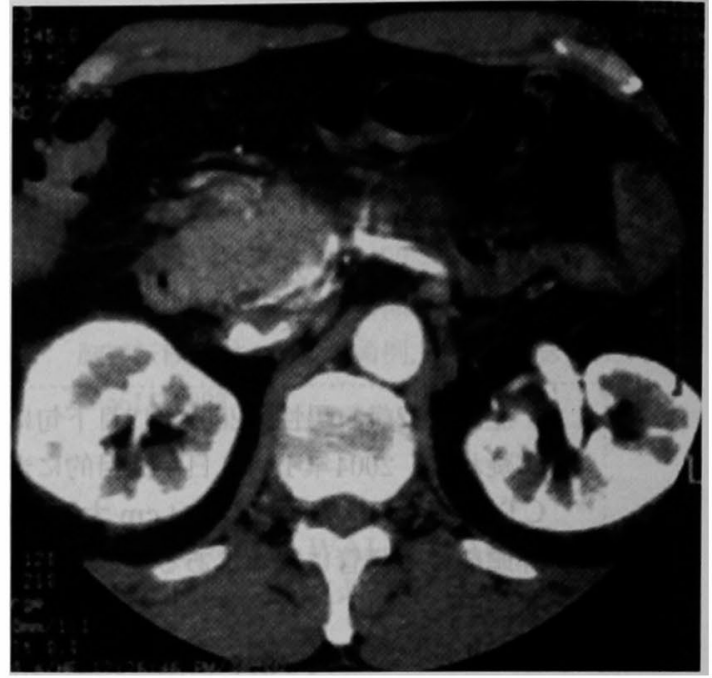

図 1 腹部造影 CT 検査：膵頭部に $4 \times 2 \mathrm{~cm}$ 大の腫瘤 と周囲リンパ節の腫大を認めた。

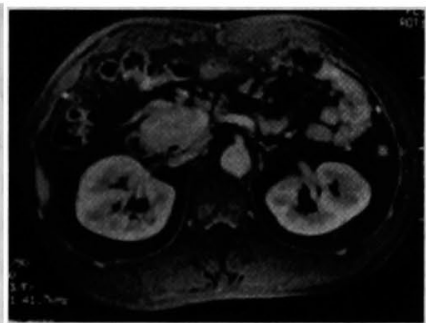

b

図 2 腹部造影 MRI 検査： a ）造影早期相では，膵頭部に造影効果 の乏しい腫瘤を認めた. b) 造影後期相では, 増強する $4 \mathrm{~cm}$ 大の腫 瘤を認めた。

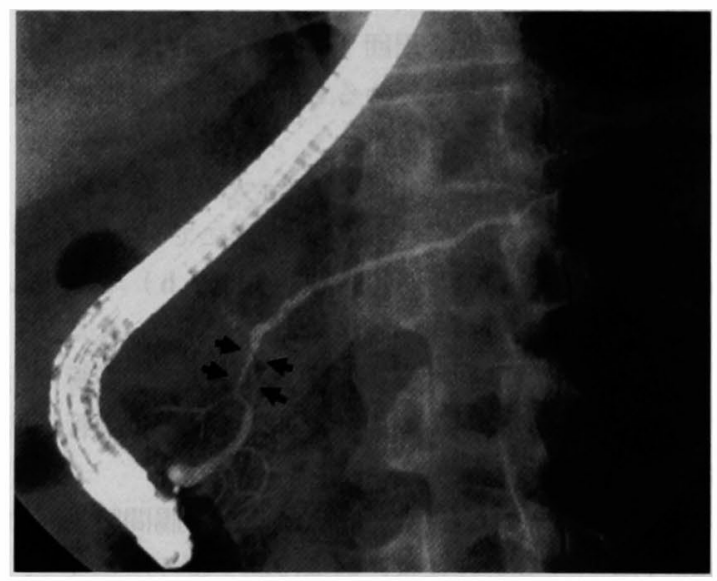

図 3 ERCP 検査：膵頭部の主膵管は圧排・狭窄を認め たか，壁はスムースで末梢主膵管の拡張も認めなかった。
所見は認めなかった。

FDG-PET 検査（図 4)：膵頭部から尾部にかけ糖 代謝の比較的強い元進を認めた.膵全体の集積であり, 活動的な比較的強い炎症があると考えられた。悪性所 見を思わせる限局した集積は認めなかった。

以上より膵癌より腫瘤形成性膵炎やアルコール性な どの良性疾患の可能性が強く, また抗核抗体が80倍, IgG4 92 と軽度高值より自己免疫性膵炎の可能性もあ り, 手術を施行せず保存的加療を継続することとした. 症状・採血データは改善し, 本人とも相談しステロイ ド療法は施行せずに経過観察とし2004年 2 月 1 日退院 となった。

腹部 CT 検査 (2004年 3 月30日) (図 5 ) : 膵全体が著 明に縮小し，周囲のリンパ節も縮小していた。 


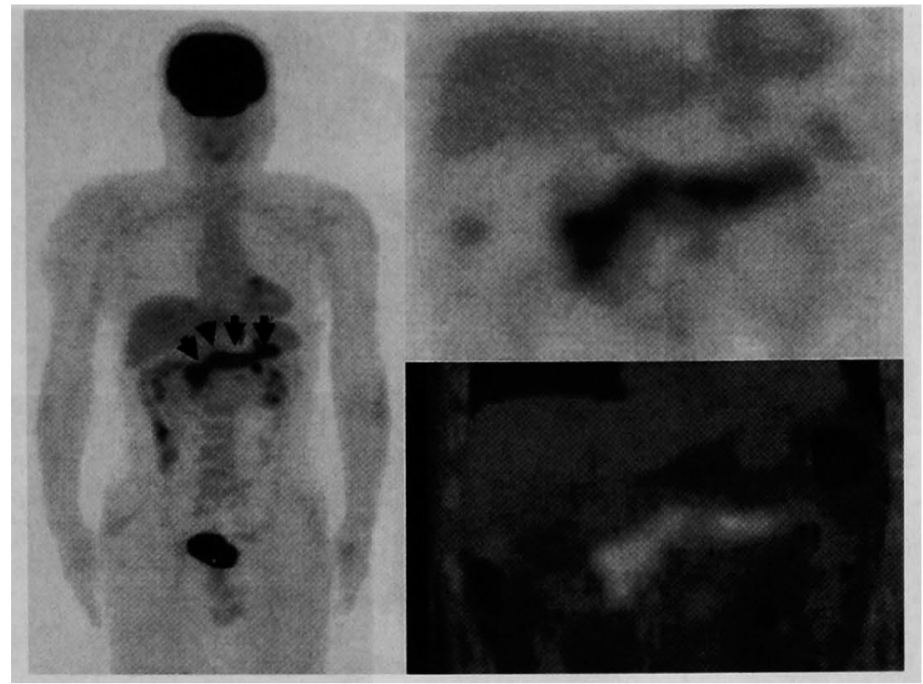

园 4 FDG-PET 検查：脑頭部から尾部にかけ膵全体に楉代謝の比較的 強い充進を認めた。

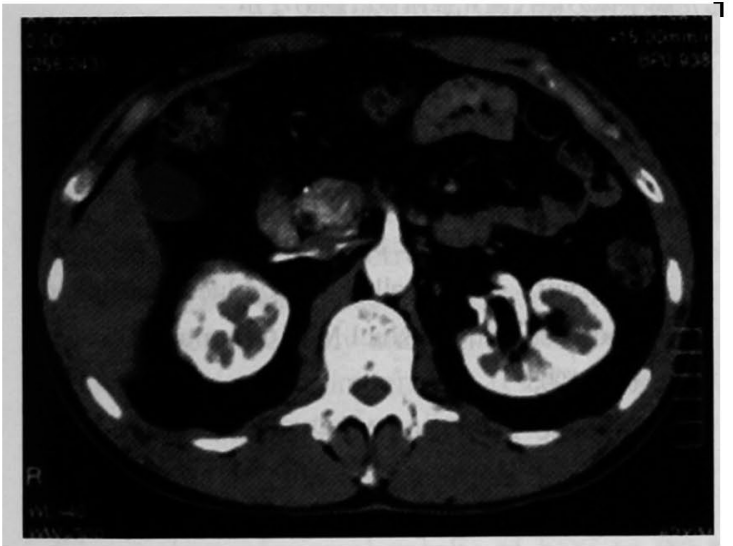

図 5 腹部造影 CT 検查（ 3 カ月後）：脺全体が著明に縮 小し, 周囲のリンパ節も縮小した.

FDG-PET 検査（図 6 ）：前回指摘した脺へのびま ん性の集積增加所見は指摘できなかった。その他の部 位にも悪性を思わせる異常部位は指摘されなかった。

以上より膵癌は勿論のこと, 腫瘤形成性膵炎や自己 免疫性膵炎ではなく，一過性に膵頭部腫大をきたした アルコール性脺炎であったものと考えられた。

$$
\text { 考察 }
$$

超音波・CT・MRI などの画像診断法が組織の形態変 化をとらえて良悪性の鑑別などを行う形態診断である のに対し，F-18標識フルオロデオキシグルコース (FDG)を用いたポジトロン断層法 (PET) は腫㵧組
織における活発な糖代謝を画像化する代謝画像であ る. 形態変化たけでは捉えられない腫瘍と緎維化巣の 鑑別が可能で，わが国では1997年より高度先進医療と して一般臨床の場で盛んに用いられるようになり， 2002年 4 月より保険診療として認可され, 疾患におい ても良悪性の鑑別に用いられるようになってきた。 FDG-PET は腫瘤形成性膵炎の診断において優れて おり，その診断能はすでに世界的に確立されてい $3^{(1)-4)}$. 東ら 5 は, 膵疾患での良悪性鑑別診断能は sensitivity $97.2 \%$, specificity $84.3 \%$, accuracy $94.0 \%$ て あったと報告している，偽陽性例は，急性膵炎，自己 免疫性脺炎等に認められた。活動性の炎症細胞（好中 球・リンパ球・マクロファージなど）には FDGが取り 込まれるため6), 強い炎症を伴う膵疾患は高集積を示 す.炎症が脺全体にびまん性に起こる場合, FDG-PET での集積パターンから鑑別診断は可能だが，自己免疫 性膵炎でも時に腫瘤形成性膵炎の形態をとることがあ り,この場合には FDG-PETでも診断は困難である゙. このため,むしろ FDG-PET の適応を絞ってこれら活 動性の炎症を除外して診断すべきとの報告もみられ $3^{8)}$. 強い炎症性疾患では通常の 1 時間像では高集積 を示し，鑑別に難渋することがあるが，遅延型 FDGPET 撮像法が炎症性膵疾患の良悪性鑑別診断に有用 であることが示されだ9.これは腫晹組織は metabolic trapping のため, 通常の撮像時間を過ぎても腫瘍への FDG の集積は漸增して，2 時間の遅延相の診断ではよ 

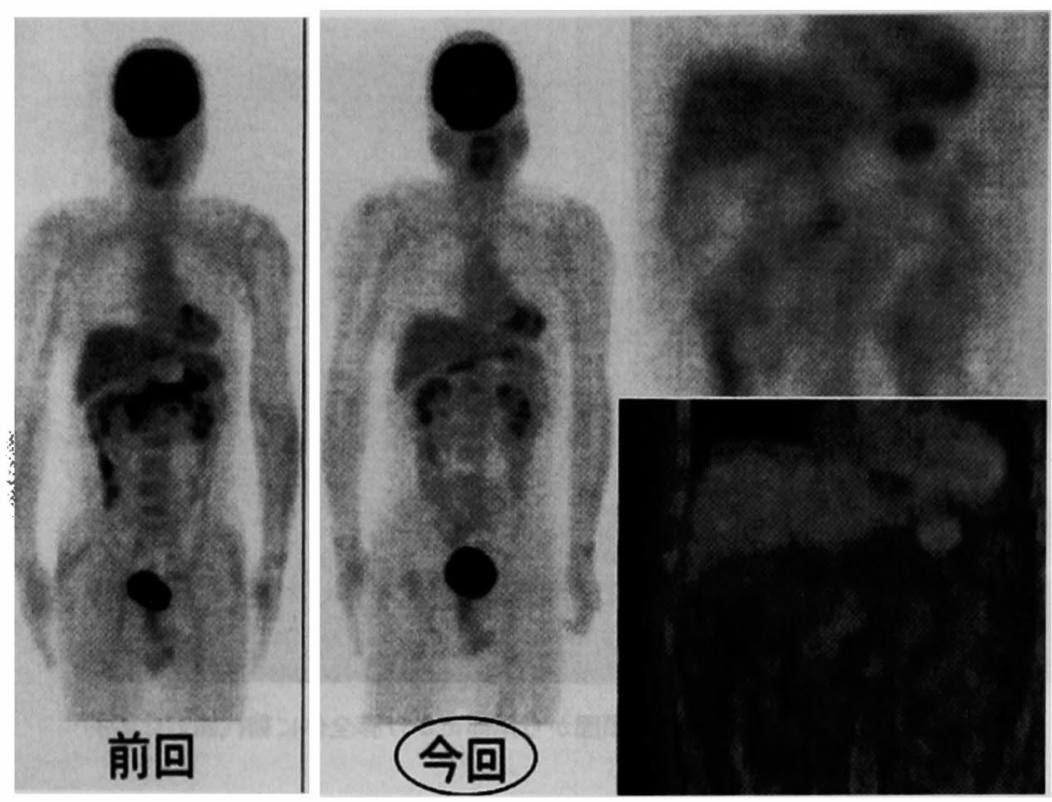

図 6 FDG-PET 検査 ( 3 力月後)：前回指摘した膵全体の糖代謝立進所見は認めなか った.

り腫瘍/正常比（T/N ratio）の高い良好な FDG-PET 画像が得られる。逆に正常膵組織や炎症性膵疾患では 集積が経時的に低下していくことが多い.腫場の FDG 集積はその腫瘍細胞密度に影響を受けるとされ $3^{10) 11)}$. 膵臓癌は一般に間質成分の多い管状腺癌であ り, 細胞密度がやや低く, scirrhous type は腫湟細胞 密度が極端に低いため偽陰性を呈することもある。わ が国でも膵癌はますます増加の一途をたどっている。 ERCP や超音波内視鏡などに比して, FDG-PET の安 全性は高く，患者への侵襲は非常に低い。しかも一度 に全身の検索が可能で，脺癌だけでなく多種多様な癌 の screening が同時に可能である. FDG-PET 検查が 全国的に一般化され，適切な診断体系の中で有効に活 用されることが，膵疾患の診断・治療に大きく関与す ると信じるものである.

\section{結語}

膵頭部腫瘤の鑑別に FDG-PET が有用であった 1 例を経験したので報告した。

\section{文献}

1) Bares R, Klever P, Hellwig D, et al : Pancreatic cancer detected by positron emission tomogra phy with $18 \mathrm{~F}$-labelled deoxyglucose: Method and first results. Nucl Med Commun 14 : 596601, 1993

2) Delbeke D, Rose DM, Chapman WC, et al: Optimal interpretation of FDG PET in the diagnosis, staging and management of pancreatic carcinoma. J Nucl Med 40:1784-1791, 1999

3) Kato T, Fukatsu H, Ito K, et al : Fluorodeoxyglucose positron emission tomography in pancreatic cancer : An unsolved problem. Eur J Nucl Med 22:32-39, 1995

4) Inokuma $\mathrm{T}$, Tamaki $\mathrm{N}$, Torizuka $\mathrm{T}$, et al: Evaluation of pancreatic tumors with positron emission tomography and F-18 fluorodeoxyglucose : Comparison with CT and US. Radiology $195: 345-352,1995$

5）東 達也，佐賀恒夫，小西淳二：良悪性の鑑別に おける FDG-PET の役割. 消外 $24: 1531-$ 1536, 2001

6) Higashi T, Fisher SJ, Brown RS, et al : Evalua- 
tion of the early effect of local irradiation on normal rodent bone marrow metabolism using FDG : Preclinical PET studies. J Nucl Med 41 : 2026-2035, 2000

7) Nakamoto $Y$, Saga $T$, Ishimori $T$, et al : FDGPET of autoimmune-related pancreatitis : Preliminary results. Eur J Nucl Med 27 : 18351838,2000

8) Shreve $P D$ : Focal fluorine-18 fluorodeoxyg. lucose accumulation in inflammatory pancreatic disease. Eur J Nucl Med 25 : 259-264, 1998

9) Nakamoto $Y$, Higashi T, Sakahara H, et al : Delayed (18) fluoro-2-deoxy-D-glucose positron emission tomography scan fou differentiation between malignant and beign lesions in the pancreas. Cancer $89: 2547--2554,2000$

10) Ito $K$, Kato $T$, Ohta $T$ : Fluorine-18 fluoro-2deoxyglucose position emission tomography in recurrent rectal cancer : Relation to tumor size and cellularity. Eur J Nucl Med 23:13721377, 1996

11) Higashi $T$, Tamaki $N$, Torizuka $T$, et al : FDG uptake, GLUT-1 glucose transporter and cellularity in human pancreatic tumors. J Nucl Med $34: 1727-1735,1998$

\title{
A CASE OF A TUMOR OF THE PANCREATIC HEAD DIAGNOSED BY FDG-PET
}

\author{
Masanori KOTAKE, Hiroshi KOIZUMI, Katsuya MORITA, \\ Hiroyuki BANDO, Nozomu MURAKAMI and Tetsuji YAMADA \\ Department of Surgery, Ishikawa Prefectural Central Hospital
}

A 62-year-old man complaining of upper abdominal pain was referred to the hospital after pancreatic head cancer was suspected by abdominal computed tomography (CT) and magnetic resonance imaging (MRI) at another hospital, which showed a $4 \mathrm{~cm}$ tumor and regional lymph nodes swelling. After admission endoscopic retrograde cholangiopancreatography (ERCP) showed a short smooth stenosis of the main pancreatic duct at the pancreatic head, but did not show dilation of the main pancreatic duct at the pancreatic body and tail. Arteriography of the celiac artery and SMA showed no abnormalities. Positron emission tomography (PET) showed diffuse uptake of ${ }^{18} \mathrm{~F}$-fluorodeoxyglucose (FDG) in the entire pancreas, but no malignant findings were revealed. Conservative treatment was started with a suspicion of benign disease such as tumor forming pancreatitis or autoimmune pancreatitis. Theree months later abdominal CT scan showed no swelling of the pancreas head or lymph nodes swelling. PET did not show abnormal uptake of FDG to the pancreas. He was diagnosed as having alcoholic pancreatitis causing temorary swelling of the pancreatic head. FDG-PET is useful for differentiation between malignant and benign lesions. 